\title{
Effect of Colchicine on the Intracellular Transport of Secretory Proteins in Rat Liver Parenchymal Cells. Immunocytochemical Observations.
}

\author{
Sadaki Yokota \\ Department of Anatomy, Yamanashi Medical School, Yamanashi 409-38, \\ Japan
}

\begin{abstract}
We studied the effects of colchicine on the intracellular transport of secretory proteins in rat liver parenchymal cells using the direct immunoenzyme technique. Livers were perfusion-fixed $0.5,1$, and $2 \mathrm{~h}$ after injection of colchicine. Vibratome sections of the fixed liver were stained using peroxidase-conjugated $\mathrm{Fab}^{\prime}$ of anti-albumin or anti-fibrinogen. By light microscopy, reaction deposits showing albumin and fibrinogen were observed in the cytoplasmic granules of hepatocytes. Such stained granules decreased $30 \mathrm{~min}$ after injection, but later increased gradually and crowded in the cytoplasm. The Golgi complex stained for the proteins decreased after $30 \mathrm{~min}$ but increased in the juxtanuclear region after $60 \mathrm{~min}$. The analysis of serial sections showed that colchicine severely disturbed the spatial relationship between the Golgi apparatus and the bile canaliculus. We obtained similar results by electron microscopy; a positive reaction for albumin and fibrinogen was observed in a small number of the cytoplasmic granules after $30 \mathrm{~min}$. After $1 \mathrm{~h}$ of treatment, most of the Golgi complexes were fragmented and lost their stacked cisternae. However, they reappeared accompanied with vacuolated cisternae and secretory granules, which were partially stained for albumin and fibrinogen. After $2 \mathrm{~h}$, the secretory granules positive for both proteins accumulated further. Some of them lined a long the plasma membrane, and others made a cluster in the cytoplasm. The profiles showing exocytosis were very rarely seen. These results showed that in the first $30 \mathrm{~min}$, colchicine primarily disturbs partially the Golgi assembly but does not affect the post Golgi secretory pathway much. Later, the drug affects both the post Golgi pathway and the Golgi assembly, and it causes a marked accumulation of secretory granules.
\end{abstract}

It is well established that the secretory proteins are synthesized on membranebound polyribosomes and segregated vectorically into the lumen of the endoplasmic reticulum (ER). The proteins are then transported to the Golgi complex, where the newly synthesized proteins are packaged into the secretory granules $(9,17)$. The liver produces most of the plasma proteins. They are transported in the same way and finally secreted into the Disse space $(7,8,21,22)$.

An anti-microtubular agent, colchicine, has been shown to inhibit the release of secretory proteins $(5,12,15,16,18,24,26,27,28)$. Since the Golgi apparatus suffers severe structural damage after colchicine treatment, it has been thought that the post Golgi transport is disturbed rather than the pre Golgi transport $(3,12,16$, 
24). In the liver, colchicine virtually inhibits the secretion of albumin and other plasma proteins, and consequently causes the accumulation of the cytoplasmic granules containing lipoprotein particles in the hepatocytes $(15,22,25)$. However, it has yet to be demonstrated immunocytochemically whether or not these accumulated granules contain albumin and other plasma proteins. Previously, we have reported in detail the immunocytochemical localization of albumin in the secretory appratus of rat liver $(33,34)$. In this study, we investigate the effect of colchicine on the localization of albumin and fibrinogen in rat hepatocytes using immunoenzyme techniques.

\section{MATERIALS AND METHODS}

Antibodies. We have described elsewhere the purification of albumin and immunization of rabbits with the purified albumin (33). Rat serum fibrinogen was purified according to the method of Doolittle (4). Rabbits were immunized by the same procedures as the case of albumin (32). IgG fraction was prepared by ammonium sulfate franctionation. Fab' fragments were prepared by digestion of the IgG fraction with papain (23). Fab' fragments specific for albumin of fibrinogen were purified by affinity chromatography on albumin- or fibrinogen-coupled Sepharose 6B. Preparation of Fab'-peroxidase conjugates was described previously (32).

Administration of colchicine to rats. Male Wistar rats, weighing $180-200 \mathrm{~g}$, were used. The animals were fasted $18 \mathrm{~h}$ before the experiments. Colchicine $(0.4 \mathrm{mg} / 100 \mathrm{~g}$ of body weight) or physiological saline was administrated by intravenous injection into the femoral vein.

Tissue preparation and immunocytochemical procedures. Liver was perfused with the fixative through the portal vein at 30,60 , and $120 \mathrm{~min}$ after injection. The perfusion was continued for $5 \mathrm{~min}$ and the excess fixative was removed by $3 \mathrm{~min}$ perfusion with physiological saline. The fixative consisted of $4 \%$ paraformaldehyde, $0.02 \%$ glutaraldehyde, $4 \%$ polyvinylpyrorridone, $0.1 \% \mathrm{NaN}_{3}, 0.01 \% \mathrm{CaCl}_{2}$, and $0.1 \mathrm{M}$ cacodylate buffer, $\mathrm{pH} 7.4$. The liver was cut into $50 \mu \mathrm{m}$ thick tissue sections with a Vibratome. The sections were treated with $0.1 \mathrm{M}$ lysine in $0.15 \mathrm{M}$ cacodylate buffer, $\mathrm{pH} 7.4$ for $15 \mathrm{~min}$ to block the nonspecific absorption of antibodies. After permeation with $0.02 \%$ Triton WR-1339, some tissue sections were incubated with peroxidase-conjugated specific $\mathrm{Fab}^{\prime}(50 \mu \mathrm{g} / \mathrm{ml})$. Others were incubated with peroxidase-conjugated nonspecific $\mathrm{Fab}^{\prime}(100 \mu \mathrm{g} / \mathrm{ml})$ overnight at $4^{\circ} \mathrm{C}$. After being washed in physiological buffered saline (PBS), they were fixed with $2 \%$ glutaraldehyde. This was followed by 15 min-incubation with diaminobenzidine (DAB)- $\mathrm{H}_{2} \mathrm{O}_{2}$ medium for peroxidase. These sections were postosmicated and then processed to dehydration and embedding in Epon.

Semi-thin sections were cut with glass knives, mounted on glass slides, and then examined by a Nikon light microscope. Some serial sections ( $1 \mu \mathrm{m}$ thick) were cut and analyzed for their distribution pattern of albumin-positive granules in hepatocytes. Golgi contour or positive large granules $(>1.5 \mu \mathrm{m})$ per a cell were counted for each section. Ultra-thin sections were cut with a diamond knife and mounted on copper grids. After staining with lead citrate, the sections were examined in a Hitachi $\mathrm{H} 600$ electron microscope at $100 \mathrm{kv}$.

\section{RESULTS}

Light microscopy. [Albumin] In control animals injected with physiological saline, the localization of albumin was similar to what we have described previously $(33,34)$. Albumin was detected in the cytoplasmic granules of hepatocytes and 
sinus-lining cells (Fig. 1A). In the hepatocytes, some positive granules located in the perinuclear region (Fig. 1A, arrowheads). These seemed to be the Golgi complexes. Others were present in the cytoplasm or lined up along the sinusoidal front (Fig. 1A, arrows). These seemed to be secretory granules. Thirty min after injection of colchicine, most of the Golgi-related reaction deposits disappeared. Only a few deposits were present in the pericanalicular region (Fig. 1B, arrowheads). Most of the secretory grannules that were present in the cytoplasm disappeared but some granules beneath the sinusoidal surface were still detectable (Fig. 1B, arrows). Diffuse cytoplasmic staining was noted. This staining has been previously demonstrated to show the reaction in rough ER (33). After $1 \mathrm{~h}$ of treatment, albumin-containing granules increased markedly. They varied in size and were dispersed throughout the cytoplasm (Fig. 1C). Some large granules were noted in the perinuclear region (Fig. 1C, arrowheads). The endoplasmic reticulum, including the nuclear envelope, was also stained. After $2 \mathrm{~h}$ of colchicine injection, the albumin-containing granules accumulated further, some of which crowded densely in the perinuclear or peribiliary regions (Fig. 1D, arrowheads).

[Fibrinogen] In control animals injected with physiological saline, a reaction product showing the antigenic sites for fibrinogen was observed in the cytoplasmic granules of hepatocytes and in granules of sinus-lining cells (Fig. 2A). The positive granules were considerably fewer when compared with albumin. The staining profiles showing the Golgi complex were rarely seen (Fig. 2A, arrowhead). No marked difference was observed until $1 \mathrm{~h}$ after the injection of colchicine (Fig. 2B and C). After $2 \mathrm{~h}$, however, the positive granules appeared in number and were dispersed throughout the cytoplasm of the hepatocytes (Fig. 2D). Some of them were located in juxtanuclear or pericanalicular region, showing the Golgi complex (Fig. 2D, arrowheads). This staining pattern was quite similar to that for albumin.

We analyzed the staining pattern for albumin using $1 \mu \mathrm{m}$-thick serial sections of the treated and untreated rat livers. In the untreated rat liver, fibrillar or rod-like staining showing the Golgi apparatus was located around bile canaliculus in all serial sections (Fig. 2E, left half). The result indicated that, usually, the Golgi apparatus of hepatocytes has a certain spatial association with the bile canaliculus. However, in the colchicine-treated rat liver, no fibrillar staining was noted, but most of the stained granules were round and scattered in the cytoplasm of hepatocytes, hence the spatial relationship between the Golgi apparatus and the bile canaliculus was severely disturbed (Fig. 2E, right half). Since we could not identify the Golgi contour after colchicine treatment, we thought that positive large grannules ( $>1.5 \mu \mathrm{m}$ in diameter) were the Golgi complexes themselves or derived from them. Then, we counted the number of such granules per a cell. About 4-5 pieces of the Golgi contour per a cell were found in the untreated liver, whereas about 812 pieces of the large granules per a cell were counted at $1 \mathrm{~h}$ after colchicine injection. The result suggested the fragmentation of the Golgi apparatus by colchicine treatment.

Electron microscopy. The fine structural localization of albumin in the liver parenchymal cells of untreated rat was quite similar to previous studies $(33,34)$. Namely, albumin was localized in the secretory apparatus, including rough-surfaced endoplasmic reticulum (rER), Golgi lamellae, tubulo-vesicular network at the trans Golgi region, and secretory granules (Fig. 3). After $30 \mathrm{~min}$ of colchicine injection, the stacked cisternae of the Golgi apparatus were partiallyy disturbed. Some cisternae were dilated or vacuolated (Fig. 4A). The tubulo-vesicular network of the 

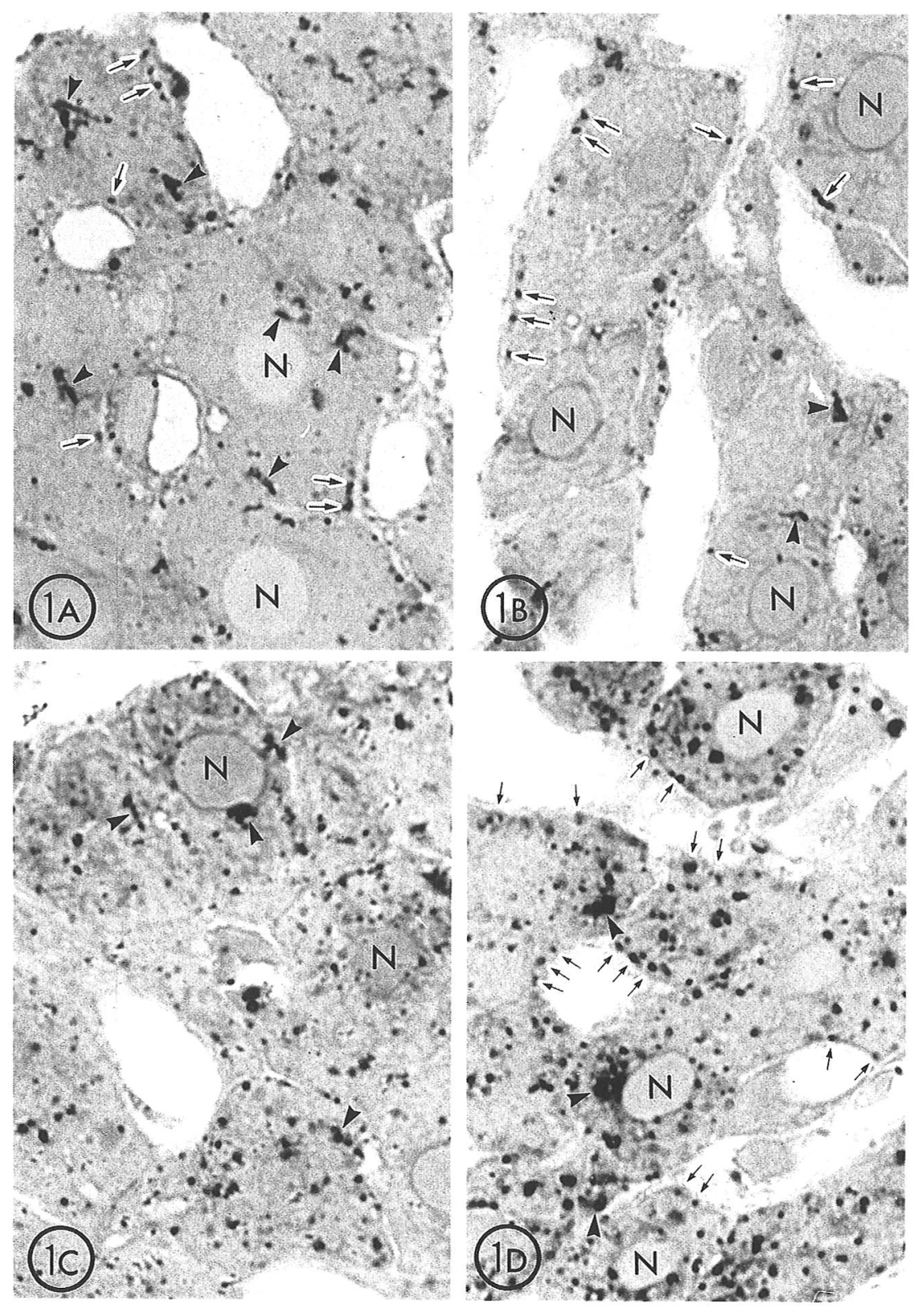

Fig. 1. Localization of albumin in rat liver. N: nucleus of hepatocytes. $\times 1,400$ for all pictures. $1 \mathrm{~A}$. Normal rat liver stained for albumin. Reaction deposits showing albumin are seen in secretory granules, some of which are located in the sinusoidal front (arrows). Relatively large granules correspond to Golgi apparatus (arrowheads). 1B. After $30 \mathrm{~min}$ of injection of colchicine, the liver was fixed. Granular staining is reduced markedly. Some secretory granules line up along the sinusoidal surface (arrows). The reaction showing the Golgi apparatus is seen in a few cases (arrowheads). 1C. After $1 \mathrm{~h}$ of treatment. Discrete granular staining is markedly augmented. In the juxtanuclear or pericanalicular area, the reaction showing the Golgi apparatus is seen (arrowheads). 1D. $2 \mathrm{~h}$ after treatment. Granular staining increases conspicuously. Many granules are located in the cytoplasm of the sinusoidal front (arrows). The Golgi complexes are heavily stained (arrowheads). 

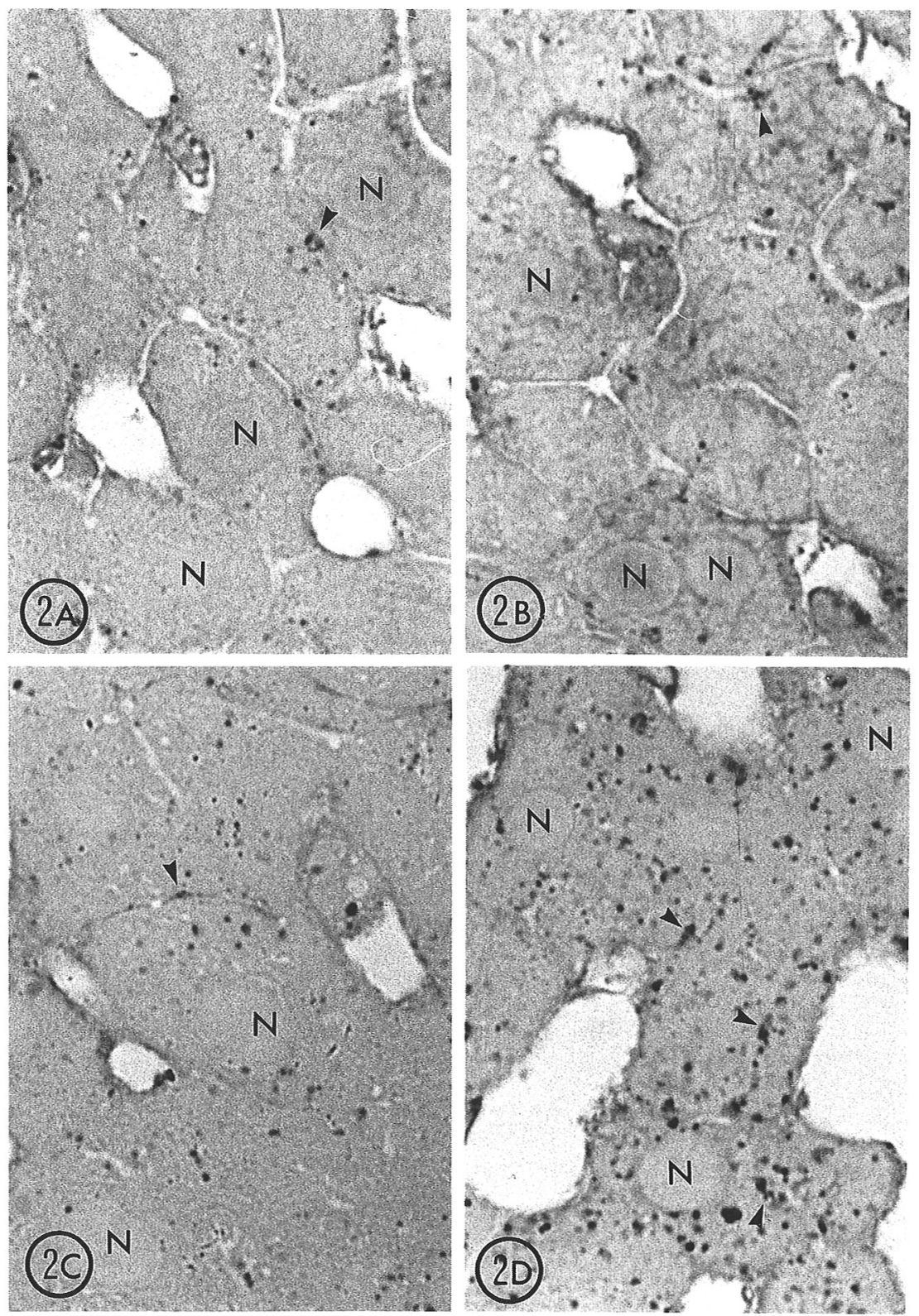

Fig. 2. Localization of fibrinogen in rat liver. N: nucleus of hepatocytes. $\times 1,400$ for all pictures. 2A. Liver of untreated rat. A few granules are stained. The granule suggesting the Golgi apparatus is seen (arrowhead). 2B. $30 \mathrm{~min}$ after injection of colchicine. Positive granules did not increase. A Golgilike granule is stained (arrowhead). 2C. After $1 \mathrm{~h}$ of treatment. Positive granules markedly increase. Golgi-like staining is noted (arrowhead). 2D. Positive granules are vastly augmented and dispersed in the cytoplasm. Some of them seem to be the Golgi apparatus (arrowheads). 


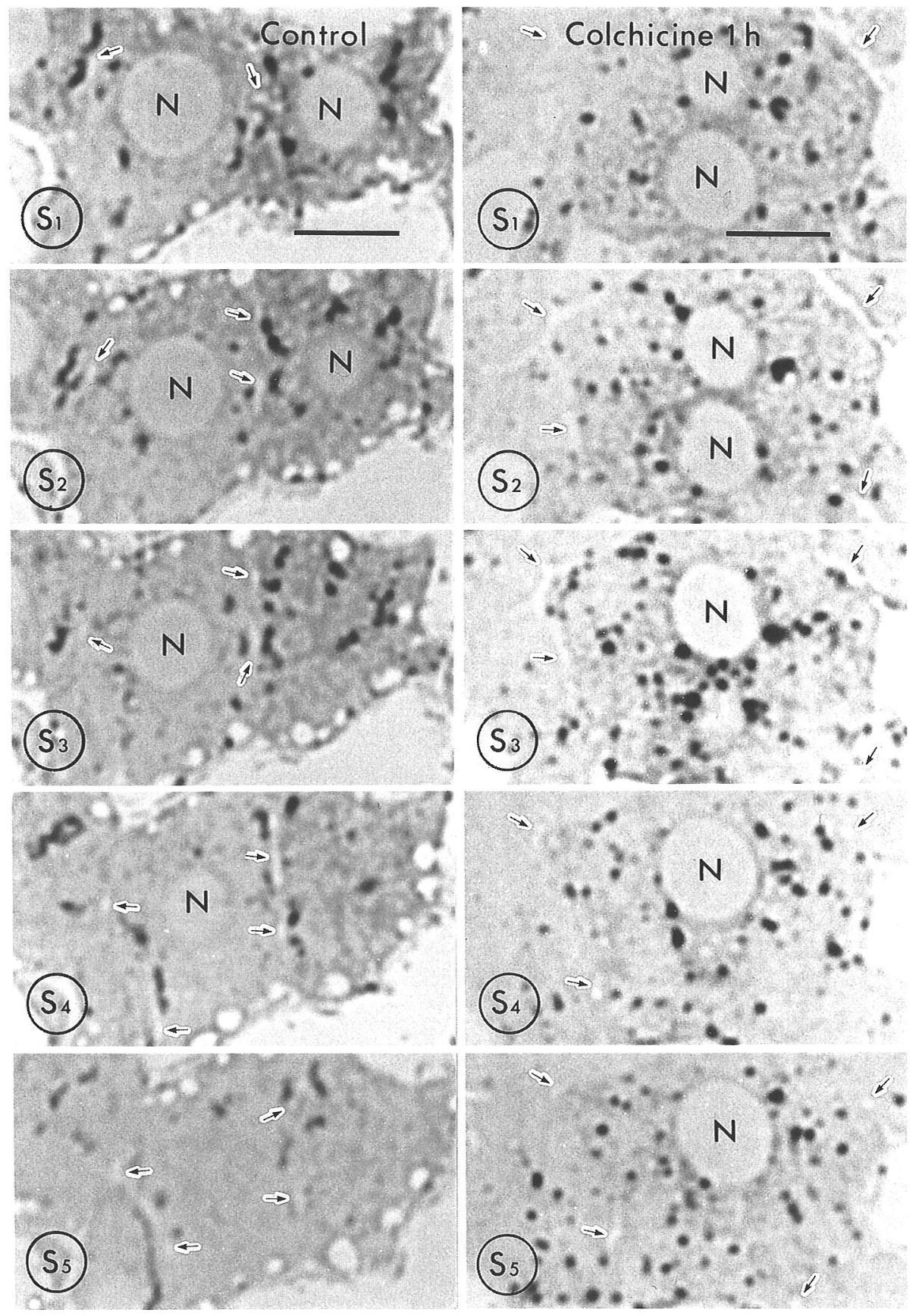

Fig. 2E. Distribution of the cytoplasmic granules stained for albumin in serial sections ( $1 \mu \mathrm{m}$ thick each). The left half (control) shows 5 serial sections of normal rat liver. The right half (colchicine $1 \mathrm{~h}$ ) shows 5 serial sections of rat liver fixed at $1 \mathrm{~h}$ after colchicine injection. In the control liver, fibrillar staining is present around the bile canaliculi (arrows), whereas in the treated liver, the stained granules are round and do no crowd around bile canaliculi (arrows), and are scattered throughout the cytoplasm. The number (S1-S5) at lower left is the section number. N: Nuclei. Bar: $5 \mu \mathrm{m}$. $\times 2,800$ 

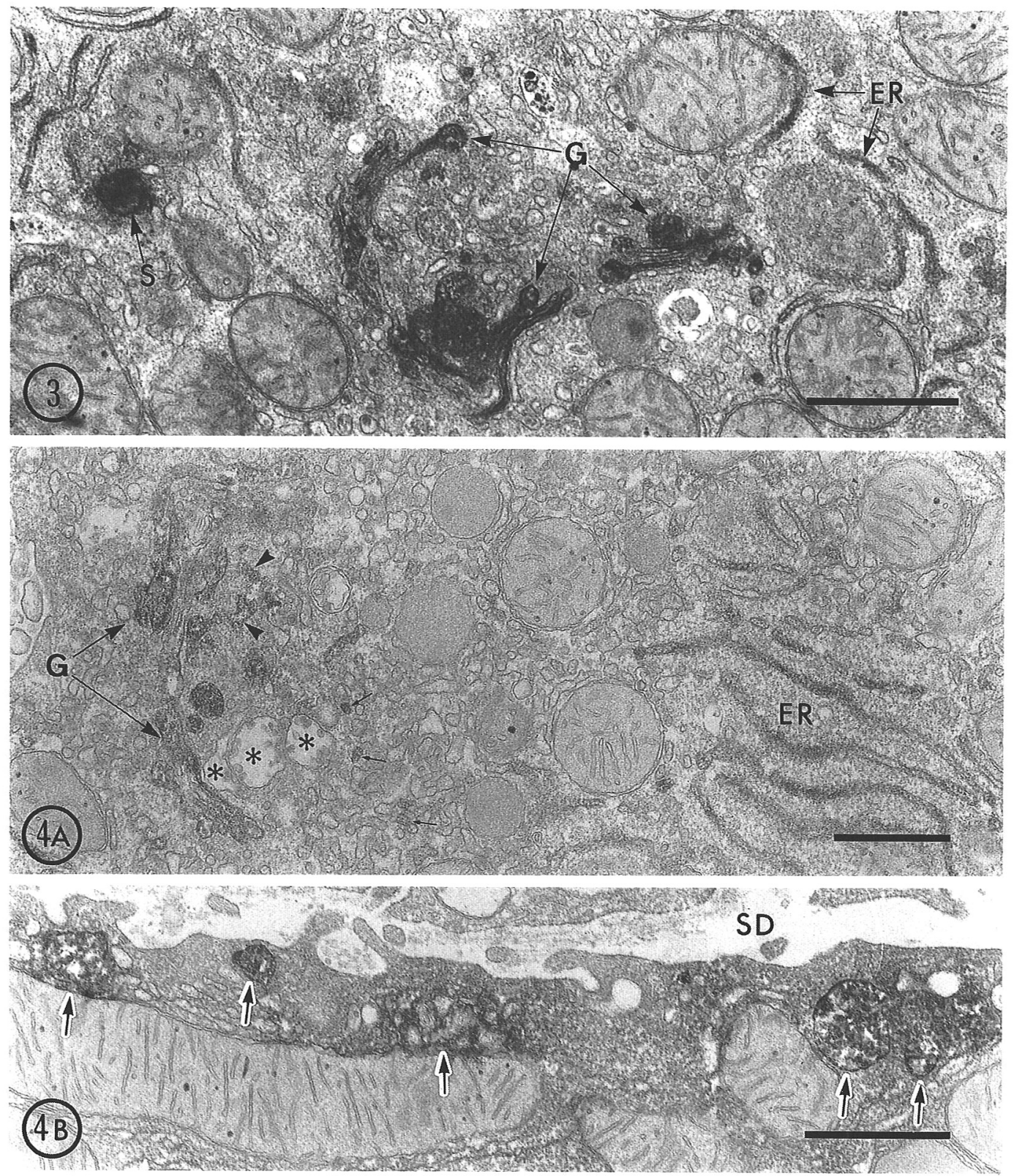

Fig. 3. Localization of albumin in a hepatocyte of untreated rat. A reaction product showing a albumin is seen in the stacked cisternae of Golgi apparatus (G), endoplasmic reticulum (ER), and secretory granules $(\mathrm{S})$. Bar: $1 \mu \mathrm{m}$. $\times 21,000$

Fig. 4. Localization of albumin in hepatocytes of rat after $30 \mathrm{~min}$ of colchicine administration. 4A. Juxtanuclear area of a hepatocyte. Reaction deposits for albumin are seen in endoplasmic reticulum (ER) and Golgi complex (G). Some of the trans Golgi cisternae $\left(^{*}\right)$ are vacuolated. The reaction is present in tubulo-vesicular network at the trans Golgi region (arrowheads) as well as in some transport vesicles (arrows). Most of the smooth vesicles are negative for staining. Bar: $1 \mu \mathrm{m} . \times 16,000$. 4B. Sinusoidal front of a hepatocyte. Secretory granules stained for albumin (arrows) are located deneath the plasma membrane. SD: Disse space. Bar: $1 \mu \mathrm{m} . \times 20,000$ 

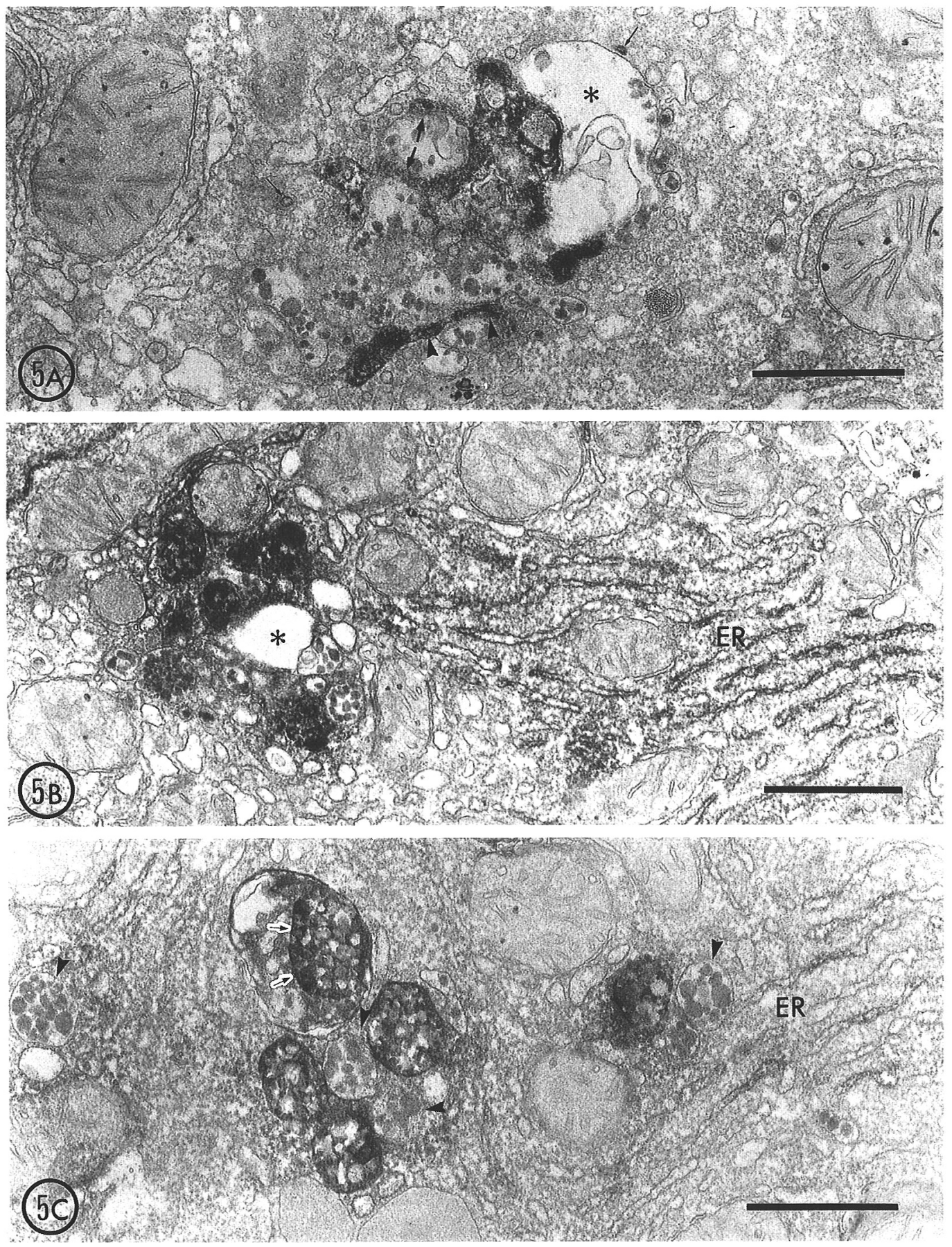

Fig. 5 
trans Golgi region persisted in part. In such Golgi apparatus, a reaction product for albumin was present in some stacked cisternae and the tubulo-vesicular network, but not in the vacuolated cisternae (Fig. 4A). Many of the secretory granules were located along the sinusoidal front, but a few were observed along the lateral membrane, most of which were stained for albumin (Fig. 4B). After $1 \mathrm{~h}$ of treatment, the disintegration of the Golgi complex was more severe. They were fragmented and the stacked cisternae were no longer discernible (Fig. 5A, B). Albumin was detected in some vacuolated cisternae (Fig. 5A, B). Some attenuated cisternae containing albumin wrapped the cisterna, which was negative for albumin but contained liopoprotein particles (Fig. 5A). Albumin was detected in the citernae of rER which were somewhat dilated (Fig. 5B, C). In the cytoplasm, many secretory granules were noted (Fig. 5C). Most of them were stained for albumin, but a few contained lipoprotein particles instead of albumin. Some large granules contained albuminpositive smaller granules (fig. 5C). After $2 \mathrm{~h}$ of treatment, some Golgi complexes recovered in part their stacked cisternae. However, most of them were still fragmented and vacuolated (Fig. 6A, B). Small dilated smooth vesicles were observed around the Golgi apparatus; they were mostly negative for albumin and contained no lipoprotein particles (Fig. 6A, B). The secretory granules positive for albumin further increased in number and were dispersed throughout the cytoplasm (Fig. 6C).

The localization pattern of fibrinogen was similar to that of albumin. In the hepatocytes of untreated rats, fibrinogen was detected mainly in the Golgi cisternae, vesicles, and vacuoles (secretory granules) (Fig. 7A). Little or no fibrinogen was detected in the rER. This suggests that, in a normal state, the concentration of fibrinogen in the secretory apparatus is at a considerably low level. At $30 \mathrm{~min}$ after injection of colchicine, fibrinogen and lipoprotein particles co-existed in the Golgi cisternae, which were partially dilated and fragmented to form vesicles (Fig. 7B). Furthermore, small segments of the rER were stained (Fig. 7B). After $1 \mathrm{~h}$, the disintegration of the Golgi complex progressed and fibrinogen was detected in the large secretory granules (Fig. 7C). After $2 \mathrm{~h}$, the secretory granules containing fibrinogen accumulated (Fig. 8A). At 1-2 h after injection, some secretory granules lined up in the cytoplasm beneath the sinusoidal surface (Fig. 8B).

In the immunocytochemical control groups which were incubated with nonspecific Fab' labeled with HRP, no reaction deposits were noted in the secretory apparatus described above (data not shown).

\section{DISCUSSION}

Morphological effects of antimicrotubular agents have been described in liver parenchymal cells $(3,12,16,24)$, and in several other cell types $(2,5,6,11,14,19$,

Fig. 5. Localization of albumin in hepatocytes of rat after $1 \mathrm{~h}$ of colchicine injection. 5A. The lamellar structure of Golgi apparatus is disrupted. The Golgi cisternae are extremely swollen and not stained for albumin $(*)$. Reaction deposits are seen in an attenuated cisterna (arrowheads) and in a tubulo-vesicular network which wraps around the vacuole (thick arrows). A few transport vesicles are stained (thin arrows). Bar: $1 \mu \mathrm{m} . \times 22,000$. 5B. Severely disrupted Golgi complex. Reaction deposits are present in the Golgi vacuoles and in the endoplasmic reticulum (ER). Negative vacuole is also noted $\left({ }^{*}\right)$. Bar: $1 \mu \mathrm{m}$. $\times 20,000$. 5C. A cluster of secretory granules. Some granules are positive for albumin but others are negative (arrowheads). Sometimes, a reaction negative granule includes a positive granule (arrows). Albumin is detected in the endoplasmic reticulum (ER). Bar: $1 \mu \mathrm{m} . \times 22,000$ 

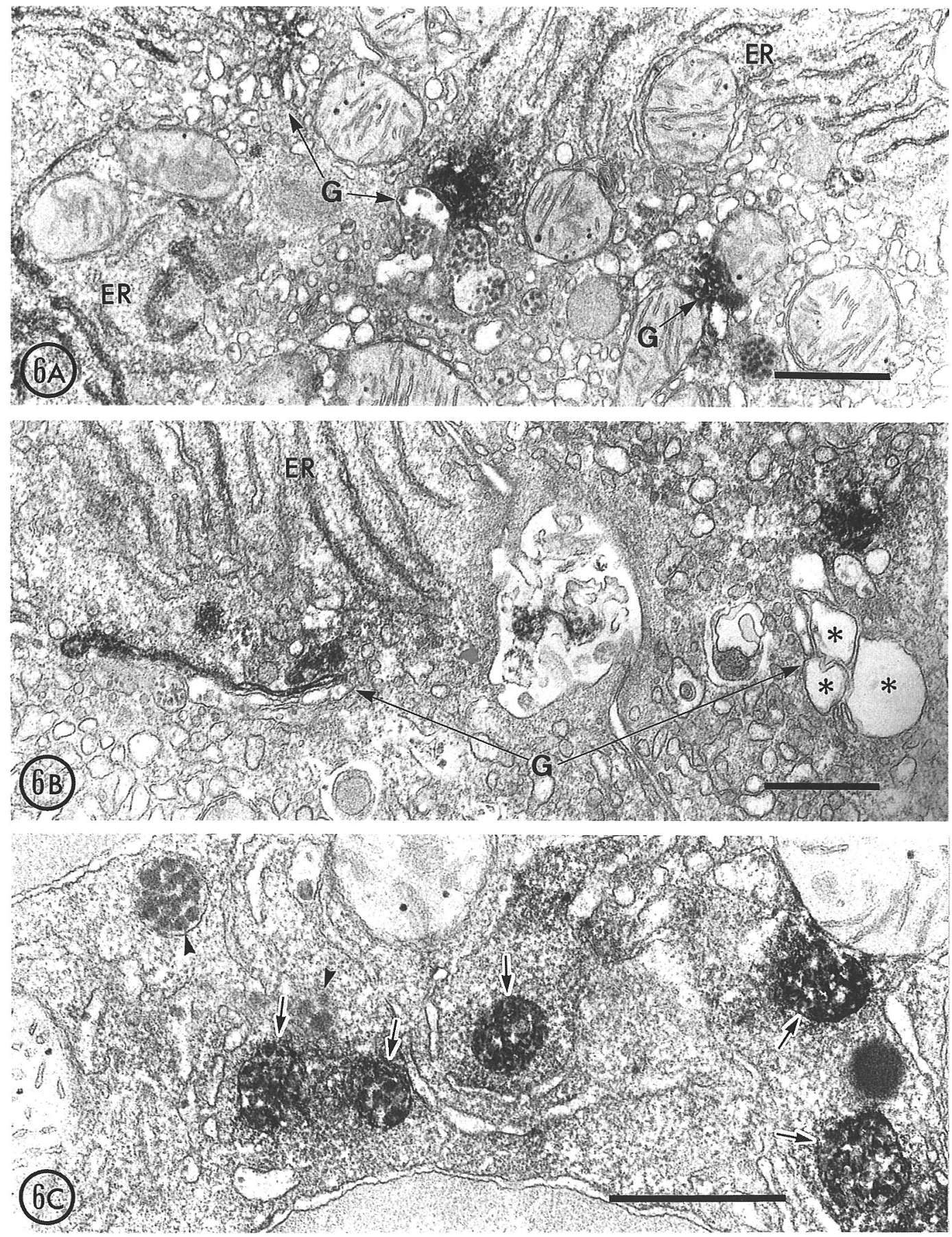

Fig. 6. Localization of albumin in hepatocytes of rat after $2 \mathrm{~h}$ of colchicine injection. 6A. Diffuse staining is seen in the disintegrated Golgi complexes $(G)$. The endoplasmic reticulum is focally stained for albumin (ER). Bar: $1 \mu \mathrm{m}$. $\times 17,000.6 \mathrm{~B}$. The Golgi apparatus recovering its integrity is seen at lower left and a disturbed Golgi complex, which has no reaction in its dilated cisternae (*) at lower right. Bar: $1 \mu \mathrm{m}$. $\times 17,000.6 \mathrm{C}$. A cluster of secretory granules. Most of them are stained for albumin (arros) but some are negative (arrowheads). Bar: $1 \mu \mathrm{m} . \times 26,000$ 

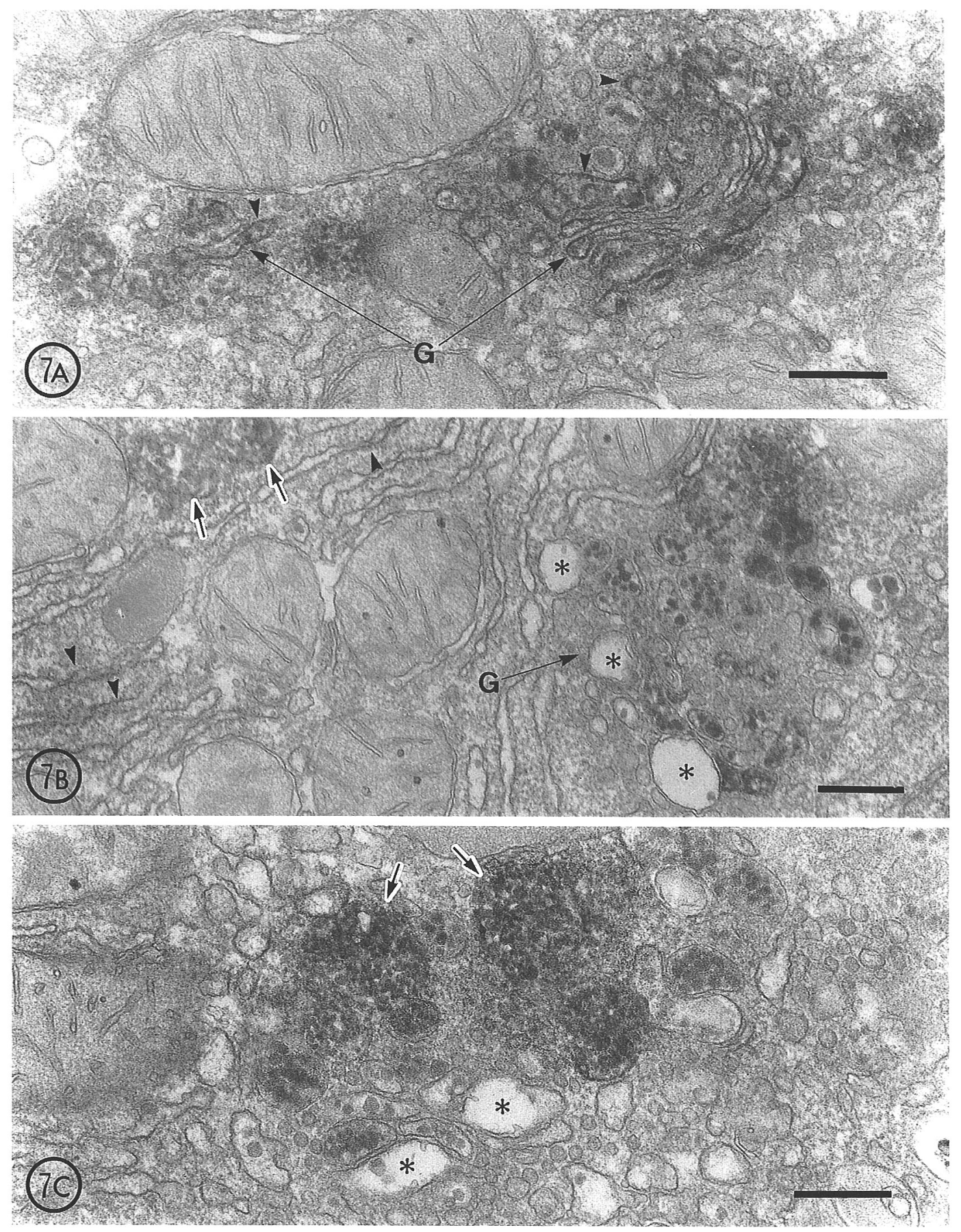

Fig. 7 

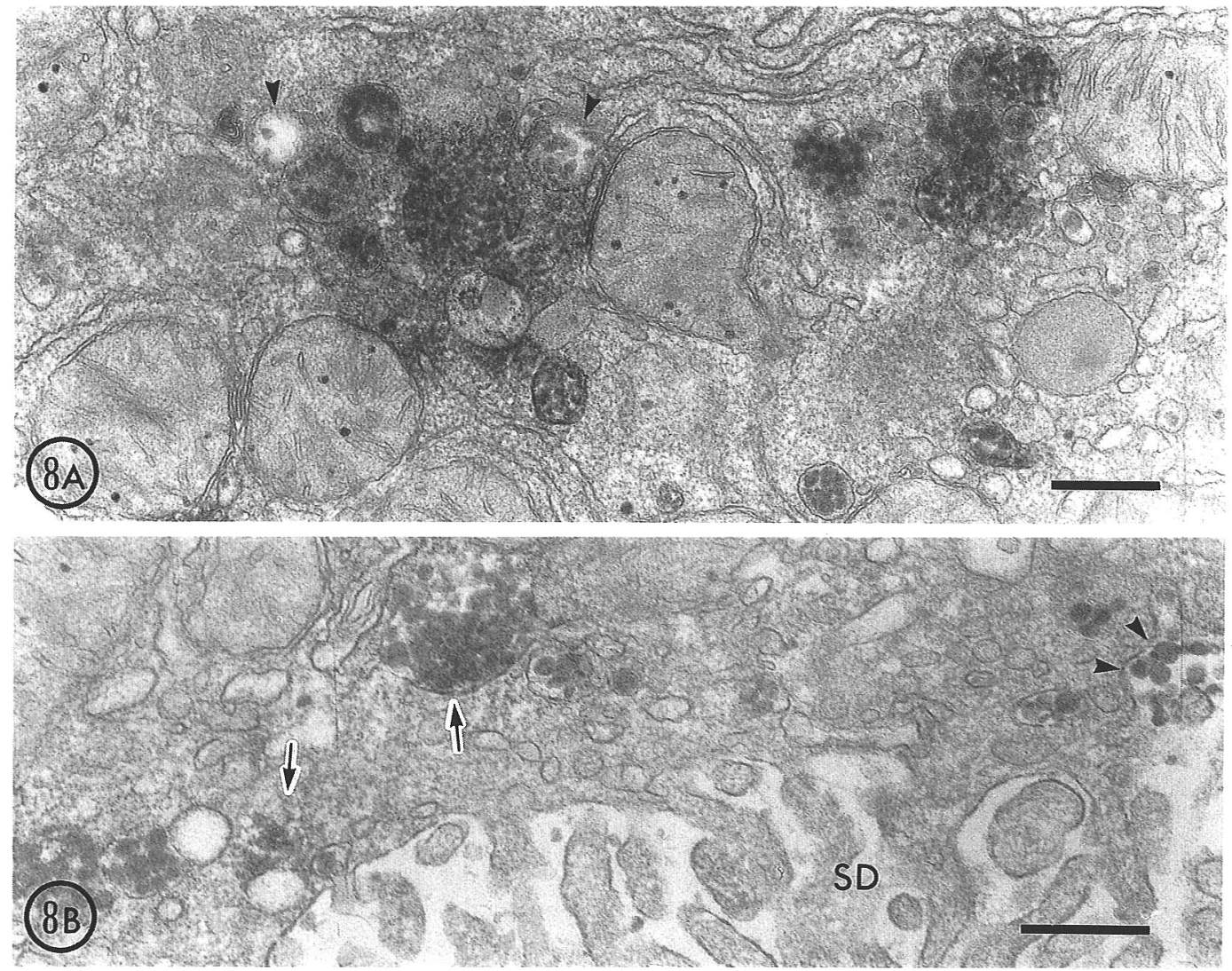

Fig. 8. Localization of fibrinogen in hepatocytes of rat after $2 \mathrm{~h}$ of cholchicine treatment. 8A. Clusters of secretory granules are shown. Reaction deposits are seen in the secretory granules. Some granules are slightly stained or not stained at all (arrowheads). Bar: $0.5 \mu \mathrm{m} . \times 25,000$. 8B. Sinusoidal front of a hepatocyte is shown. Secretory granules containing fibrinogen are present (arrows). Lipoprotein particles (arrowheads) are being released into Disse space (SD). Bar: $0.5 \mu \mathrm{m} . \times 29,000$

$20,26,30,31)$. The effects of the agents including colchicine may be summarized as follows: (a) alteration of the Golgi complex including marked accumulation of transport vesicles and vacuolation of the stacked cisternae, and (b) dispersion of secretory granules in the cytoplasm. Biochemically, it was shown that treatment with colchicine inhibits the release of secretory proteins, and consequently causes the accumulation of secretory proteins $(1,2,15,18,24,27,28,29)$. Enzyme cytochemical features of the Golgi complex disintegrated by colchicine have been

Fig. 7. Localization of fibrinogen in heaptocytes of normal and colchine-treated rats. 7A. Golgi apparatus (G) of normal rat. Reaction deposits for fibrinogen are seen in the cisternae and trans-Golgi network (arrowheads). Bar: $0.5 \mu \mathrm{m}$. $\times 29,000$. 7B. $30 \mathrm{~min}$ after treatment. Reaction product is seen in the secretory granules (arrows) and Golgi apparatus, in which vacuolated cisternae are noted and are negative for fibrinogen (*). Focal weak staining is seen in the endoplasmic reticulum (arrowheads). Bar: $0.5 \mu \mathrm{m} . \times 25,000.7 \mathrm{C}$. After $1 \mathrm{~h}$ treatment with chlchicine. Golgi apparatus is shown. Disturbance of the Golgi apparatus is noted. Fibrinogen is detected in secretory granules (arrows) but some dilated cisternae are negative for this protein $(*)$. Bar: $0.5 \mu \mathrm{m} . \times 29,000$ 
studied $(19,20)$. With the exception of report on very low density lipoprotein which is able to be seen under an electron microscope as small vesicles $(12,16,28)$, no study has been done that shows how the secretory proteins are localized in the secretory apparatus after treatment with colchicine.

In the present study, we showed the immunocytochemical localization of albumin and fibrinogen in hepatocytes after colchicine treatment. By light microscopy, reaction positive granules decreased markedly after $30 \mathrm{~min}$ of colchicine injection, when compared with untreated rat liver (Fig. 1A, B). This decrease seems to be due to the temporary inhibition of protein synthesis by colchicine. Most of the granules were located on the sinusoidal side (Fig. 2B), suggesting that the inhibition of secretion was also started. However, other biochemical data showed no inhibition of protein synthesis at a short time after colchicine treatment $(15,24)$. Therefore, it is likely that the decrease in staining at the early stage is due to other factor(s), which remain unclear. After $1 \mathrm{~h}$ of treatment, the granular staining conspicuously increased. Marked accumulation of the positive granules was observed after $2 \mathrm{~h}$. The evidence suggests that the synthesis of proteins is restarted (if it were the case) but that their secretion of them is still inhibition after $1-2 \mathrm{~h}$ of colchicine tretment.

The most conspicuous ultrastructural alteration was noted in the Golgi complex. After 30 min treatment, dilatation and vacuolization of the Golgi cisternae was started. After $1 \mathrm{~h}$, the stacked cisternae disappeared. Alternatively, a cluster of the vacuoles appeared in the juxtanuclear area. The integration of the Golgi apparatus was partially recovered after $2 \mathrm{~h}$ of treatment. In such Golgi complexes, albumin and fibrinogen were detected in some of the cisternae and vacuoles but not in all of them. In addition, the small vesicles which seemed to be transport vesicles, were located around the Golgi apparatus. Only a few of them were positive for albumin and fibrinogen. This was the same staining level as that of untreated rat liver (34). Furthermore, staining of the ER was not augmented by colchicine treatment, although they were somewhat dilated. These results show that after colchicine treatment, the examined proteins were transported to the secretory granules via the Golgi appratus whose integrity was considerably disturbed by treatment. Inhibition of the secretion seems to occur in the pathway after the Golgi complex, since a marked accumulation of secretory granules stained for both the proteins was observed.

Analysis of the serial sections $(1 \mu \mathrm{m}$ thick) showed that colchicine treatment severely disturbed the spatial relationship between the Golgi apparatus and bile canaliculus. In the untreated rat liver, fibrillar staining indicating the Golgi apparatus was located around the bile canaliculus, whereas in the treated animals stained granules did not crowd around the bile canaliculus, whereas in the treated animals stained granules did not crowd around the bile canaliculus but were scattered in the cytoplasm. We thought that positive large granules $(>1.5 \mu \mathrm{m}$ in diameter) were the Golgi complexes or those altered by colchicine treatment. This assumption is supported by the present electron microscopical observations. Such positive large granules markedly increased after colchicine treatment. This suggests that colchicine treatment causes the fragmentation of the Golgi apparatus.

Many secretory granules were dispersed in the cytoplsm and some of them were lined up beneath the plasma membrane on the sinusoidal side. Fusion of the secretory granules with the plasma membrane was hardly seen. This seems to show that colchicine treatment disturbs the communication of the secretory granules with the plasma membrane. It is not clear where the molecular basis of this communication is formed or what it is. It was reported that colchicine treatment causes certain 
alterations in plasma membrane (13). Colchicine treatment does not disturb the conversion of proalbumin to serum albumin $(10,15,25)$. Therefore, the inhibition of secretion by colchicine could be separate from the processing of secretory proteins.

In previous studies $(33,34)$, we have shown that albumin and lipoprotein particles are transported separately by the transport vesicles from the ER to the Golgi apparatus. In the Golgi complex, where both proteins are mixed into the seccretory grannule. The transport of the proteins from the ER to the Golgi apparatus after colchicine treatment seemed to run normally, but the formation of the secretory granules was abunormal. Frequently, the secretory granules fused with each other or they were wrapped with the cisterna containing reaction deposits (Fig. 5A, B). These were not seen in the hepatocytes of untreated rat.

In conclusion, at the early stage of colchicine treatment, the Golgi assembly is partially disturbed but the post Golgi secretory pathway is not so much affected. Later, the drug affects the post Golgi pathway as well as Golgi assembly, such that the secretory granules accumulate markedly. The drug does not disturb the transport between the ER and the Golgi appratus but inhibits it between the Golgi apparatus and the plasma membrane on the sinusoidal side. Furthermore, colchicine treatment severely disturbs the spatial relationship between the Golgi apparatus and the bile canaliculus.

\section{REFERENCES}

1. Banerjee, D., C.P. Manning and C.M. Redman. The in vivo effect of colchicine on the addition of galactose and sialic acid to rat hepatic serum glycoproteins. J. Biol. Chem. 251, 3887-3892, 1976

2. Busson-Mabillot, S., A.-M. Chambaut-Guerin, L. Ovitracht, P. Muller and B. Rossignol. Microbules and protein secretion in rat lacrimal glands: Localization of short-term effects of colchicine on the secretory process. J. Cell Biol. 95, 105-117, 1982

3. De Brabander, M., J-C. Wanson, R. Mosselmans, G. Geuens and P. Drochmans. Effects of antimicrotubular compounds on monolayer cultures of adult rat hepatocytes. Biol. Cellulaire 31, $127-140,1978$

4. Doolittle, R.F. Fibrinogen and fibrin. in The Plasma Proteins, Structure, Function, and Genetic Control, ed. Putnam, F.W., Acad. Press, New York, pp. 109-161, 1976

5. EhrLICH, H.P., R. Ross and P. BornsteIn. Effects of antimicrotubular agents on the secretion of collagen. A biochemical and morphological study. J. Cell Biol. 62, 390-405, 1974

6. ERICSON, L.E. Inhibition of the intracellular transport in the mouse exocrine pancreas induced by vinblastine. Cell Tissue Res. 206, 73-81, 1980

7. Franz, C.P., E.M. Croze, J.D. Morré and G. Schreiber. Albumin secreted by rat liver bypasses Golgi apparatus cisternae. Biochim. Biophys. Acta 678, 395-402, 1981

8. Glaumann, H. Studies on the synthesis and transport of albumin in microsomal subfractions from rat liver. Biochim. Biophys. Acta 224, 206-218, 1970

9. JAMIESON, J.D. Intracellular transport and discharge of secretory proteins: Present status and future perspecives. in Transport of Macromolecules in Cellular Systems, ed. S.C. Silverstein, Dahlem Konferenzen, Berlin, pp. 273-287, 1978

10. JuDAh, J.D. and P.S. QuinN. On the biosynthesis of serum albumin. Trends Biochem. Sci. 1, 107-109, 1977

11. Kelly, P.B., C. Oliver and A.R. Hand. The effects of vinblastine on acinar cells of the exorbital lacrimal gland of the rat. Cell Tissue Res. 195, 227-237, 1978

12. Le Marchand, Y., M. Singh, F. Assimacopoulos-Jeannet, L. Orci, Ch. Rouiller and B. JeAnRenaud. A role for the microtubular system in the release of very low density lipoproteins by perfused mouse livers. J. Biol. Chem. 248, 6862-6870, 1973

13. Leoni, S., S. Spagnuolo, M.T. Mangiantini and A. Trentalance. Effect of colchicine on rat liver plasma membrane biochemical composition. Cell Molec. Biol. 28, 125-129, 1982 
14. Moskalewski, S., J. Thyberg and U. Friberg. In vitro influence of colchicine on the Golgi complex in A- and B-cells of guinea pig pancreatis islets. J. Ultrastruc. res. 54, 304-317, 1976

15. Oda, K., Y. Misumi and Y. IKehara. Disparate effects of monensin and colchicine on intracellular processing of secretory proteins in cultured rat hepatocytes. Eur. J. Biochem. 135, 209216,1983

16. Orci, L., Y. Le Marchand, A. Singh, F. Assimacopoulos-Jeannet, Ch. Rouiller and B. JEARENNAUd. Role of microtubules in lipoprotein secretion by the liver. Nature 224, 30-32, 1975

17. Palade, G.E. Intracellular aspects of the process of protein synthesis. Science (Wash. D.C.) 189, $347-358,1975$

18. Patzelt, C., D. Brown and B. Jeanrenaud. Inhibitory effect of colchicine on amylase serection by rat parotid glands. Possible localization in the Golgi area. J. Cell Biol. 73, 578-593, 1977

19. Pavelka, M. and A. Ellinger. Effect of colchicine on the Golgi apparatus and on GERL of rat jejunal absorptive cells. Ultrastructural localization of thiamine pyrophosphatase and acid phosphatase activity. Eur. J. Cell Biol. 24, 53-61, 1981

20. Pavelka, M. and A. Ellinger. Effect of colchicine on the Golgi complex of rat pancreatic acinar cells. J. Cell Biol. 97, 737-748, 1983

21. Peters, T. The biosynthesis of rat serum albumin. II. Intracellular phenomena in the secretion of newly formed albumin. J. Biol. Chem. 237, 1186-1189, 1962

22. Peters, T., B. Fleischer and S. Fleischer. The biosynthesis of rat serum albumin. IV. Apparent passage of albumin through the Golgi appratus during secretion. J. Biol. Chem. 246, 240244, 1971

23. PORTER, R.R. The hydrolysis of rabbit $\gamma$-globulin and antibodies with crystalline papain. Biochem J. 73, 119-126, 1959

24. Redman, C.M., D. Banerjee, K. Howell and G.E. Palade. Colchicine inhibition of plasma protein release from $\gamma$ at hepatocytes. J. Cell Biol. 66, 42-59, 1975.

25. Redman, C.M., D. banerjee, C. Manning, C.Y. Huang and K. Green. In vivo effect of colchicine on hepatic protein synthesis and on the conversion of proalbumin to serum albumin. J. Cell Biol. 77, 400-416, 1978

26. Seybold, J., W. Bieger and H.F. KeRn. Studies on intracellular transport of secretory proteins in the rat exocrine pancreas. II. Inhibition by antimicrotubular agents. Virchows Arch. A. Pathol. Anat. Histol. 368, 309-327, 1975

27. Stein, O. and Y. StEIn. Colchicine-induced inhibition of very low density lipoprotein release by rat liver in vivo. Biochim. Biophys. Acta 306, 142-147, 1973

28. Stein, O., L. SANGER and Y. Stein. Colchicine-induced inhibition of lipoprotein and protein secretion into the serum and lack of interference with secretion of biliary phospholipids and cholesterol by rat liver in vivo. J. Cell Biol. 62, 90-103, 1974

29. TaRTakoff, A.M. The secretory and endocytic Paths. in Cell Biology: A series of monographs, ed. Bittar, E.E., John Wiley \& Sons, pp. 1-235, 1987

30. Thyberg, J., S. Nilsson, S. Moskalewski and A. Hinek. Effects of colchicine on the Golgi complex and lysosomal system of chondrocytes in monolayer culture. An electron microscopic study. Cytobiologie 15, 175-191, 1977

31. Thyberg, J., A. Piasek and S. Moskalewski. Effects of colchicine on the Golgi complex and GERL of cultured rat peritoneal macrophages and epiphyseal chondrocytes. J. Cell Sci. 45, 42-58, 1980

32. YокотA, S. Immunocytochemical evidence for transendothelial transport of albumin and fibrinogen in rat heart and diaphragm. Biomed. Res. 4, 577-586, 1983

33. YокотA, S. and H.D. FAнIмI. Immunocytochemical localization of albumin in the secretory apparatus of rat liver parenchymal cells. Proc. Natl. Acad. Sci. USA 78, 4970-4974, 1981

34. YокотA, S. and H.D. FAнimi. Intracellular transport of albumin through the secretory appratus of rat liver parenchymal cells. An immunocytochemical study. Cell Struct. Funct. 12, 251-264, 1987 